\title{
Impact of TB on the survival of people living with HIV infection in England, Wales and Northern Ireland
}

\author{
Dominik Zenner, ${ }_{1}^{1,2}$ Ibrahim Abubakar, ${ }_{1}^{1,2}$ Stefano Conti, ${ }^{1}$ Rishi K Gupta, ${ }^{3}$ Zheng Yin, ${ }^{1}$ \\ Meaghan Kall, ${ }^{1}$ Michelle Kruijshaar, ${ }^{4}$ Brian Rice, ${ }^{1}$ H Lucy Thomas, ${ }^{1}$ Anton Pozniak, ${ }^{5}$ \\ Marc Lipman, ${ }^{3}$ Valerie Delpech ${ }^{1}$
}

\begin{abstract}
- Additional material is published online only. To view please visit the journal online (http://dx.doi.org/10.1136/ thoraxjn-2014-206452)
\end{abstract}

For numbered affiliations see end of article.

\section{Correspondence to} Dr Dominik Zenner, Respiratory Diseases Department, Centre for Infectious Disease

Surveillance and Control, Public Health England, London NW9 5EQ, UK; Dominik.zenner@phe.gov.uk

Received 18 October 2014 Revised 14 February 2015 Accepted 18 February 2015 Published Online First 24 March 2015

\begin{abstract}
Introduction The impact of TB disease on survival in people living with HIV in high resource settings is not well documented in the antiretroviral treatment (ART) era. We calculated TB incidence rates and compared the mortality of persons with and without HIV-TB in a UK HIV cohort in the post-ART era, to determine the impact of HIV-TB on survival in the UK.

Methods We linked the national cohort of persons (aged $\geq 15$ years) diagnosed with HIV between 2000 and 2008 in England, Wales and Northern Ireland with the national TB register and deaths from the Office of National Statistics. We compared all-cause and AIDSspecific mortality in patients with and without TB by estimating HRs using Cox regression modelling allowing for potential predictors.
\end{abstract}

Results Overall, 3188 (7.2\%) individuals developed TB infection among a cohort of 44050 HIV-diagnosed persons and 149663 person-years. The cumulative TB incidence rate was 2.13 per 100 person-years with a spike within the first 6 months after HIV diagnosis. TB coinfected patients comprised $18 \%$ of the 1880 deaths during follow-up and $79 \%$ of deaths $(n=967)$ in the year following HIV diagnosis. TB coinfection (HR 4.77, $95 \% \mathrm{Cl} 4.11$ to 5.54 ) was significantly associated with increased all-cause mortality. Analysis of AIDS-related survival showed similar results.

Discussion The unexpected high mortality in patients with HIV-TB in a population with good healthcare access and ART availability highlights the importance of improving active and latent TB case-finding among patients with HIV, and HIV-testing among patients with $\mathrm{TB}$, to ensure appropriate and prompt treatment initiation for both diseases.

\section{INTRODUCTION}

The global burden of TB and HIV coinfection remains considerable, with an estimated 1.1 million new cases in 2011 alone. ${ }^{1}$ The use of highly effective antiretroviral therapy (ART) has greatly improved survival in $\mathrm{HIV}$-infected individuals, including those with $\mathrm{TB}^{2}$ Despite this, over 430000 people coinfected with TB and HIV died globally in 2011 representing almost a third of all TB deaths ${ }^{1}$ and a quarter of HIV-related deaths. ${ }^{2}$

In the UK, the incidence of TB among adults living with diagnosed HIV fell from 3020 per

\section{Key messages}

What is the key question?

- What is the TB incidence and the impact of TB coinfection on survival of people living with HIV (PLHIV) in the era of antiretroviral treatment (ART) in the UK?

What is the bottom line?

- PLHIV continue to have high rates of TB coinfection, which are associated with unexpectedly high mortality rates, even after adjusting for confounders including CD4 count and ART.

\section{Why read on?}

- This study of a large national HIV cohort demonstrates the impact of late diagnosis and delayed treatment on mortality in the UK and highlights the need for active and latent TB case finding among people with HIV and also the need to offer and recommend HIV testing to patients with TB.

100000 in 2002 to 400 per 100000 in $2011 .^{3}$ This prominent decline coincided with a reduction in new HIV diagnoses among migrants from sub-Saharan Africa (SSA), the group most likely to have been exposed to TB. ${ }^{3}$ In addition, there was a large year on year increase in the total number of people living with diagnosed HIV infection as a result of improved survival and new HIV diagnoses leading to a larger cohort. In contrast, over the same time period the overall incidence of TB in the general population has risen, and, although a low incidence country by WHO standards, the UK now has the second highest $\mathrm{TB}$ incidence rate in Western Europe, at around 14 per $100000 .^{4}$ Approximately $4 \%$ of adult TB cases had underlying HIV infection in 2011. ${ }^{5}$

HIV-TB survival is setting specific ${ }^{2}$ and among other things, is determined by the number of patients with undiagnosed HIV, the availability of ART and the ability to detect and treat TB promptly. European cohorts have documented lower survival rates of coinfected patients in the 
East compared with the West, associated with poor access to ART. $^{6}{ }^{7}$ Improved outcomes through prompt initiation of ART and TB treatment are well documented in HIV and TB endemic areas. ${ }^{8}{ }^{9}$ However, observed outcomes from studies set in countries with poor health infrastructure may not be readily transferable to a resource-rich setting.

A recent meta-analysis of cohort studies assessing the effect of TB on mortality in persons with HIV infection found that TB was associated with an overall twofold increase in mortality. ${ }^{10}$ However, when restricted to a subset of six studies conducted in the ART era, TB coinfection no longer had a significant impact on survival. None of the ART-era studies were conducted in an industrialised country, and authors recommended that further studies are needed to be conducted in different settings, with the inclusion of documentation of exposure and adherence to ART.

While life expectancy in people treated for HIV infection in the UK has dramatically increased with the advent of ART, it remained about 13 years less than that of the general population in $2008 .{ }^{11}$ Treatment delay due to late HIV presentation is the most important predictor of short-term ${ }^{12}$ and long-term survival. ${ }^{11}$ Although TB cases continue to account for $15 \%$ of all reported AIDS cases, ${ }^{3} 13$ there is currently little understanding of the impact of TB on the survival of persons living with HIV infection. Small-scale studies have shown a decline in TB-HIV mortality following the advent of universally available ART ${ }^{14}$ and demonstrated the benefits of simultaneous TB and HIV treatment. ${ }^{15}$

The UK has well-established diagnostic facilities for TB and HIV infection and universal availability of ART and anti-TB treatment. In addition, comprehensive surveillance and monitoring data collected through the National Health Service provide a unique opportunity to evaluate the impact of clinical and public health policies. In this study, we use comprehensive data from the national HIV cohort linked to national TB surveillance data and deaths from vital statistics to present TB incidence density rates from the time of HIV diagnosis and assess the impact of TB coinfection on the survival of HIV-diagnosed persons. In contrast to most clinical cohorts, persons are enrolled in this national HIV cohort at the time of HIV diagnosis (allowing capture of the two-thirds of TB and HIV coinfections diagnosed simultaneously). Furthermore, the annual loss to follow-up in this national HIV cohort is very low $(<5 \%)$ due to comprehensive data returns (including transfers) from all HIV services across the UK linked to service funding. ${ }^{16}$

The main objectives of the study were to compare the survival of HIV-diagnosed patients with and without TB coinfection and assess the impact of $\mathrm{TB}$ coinfection on survival after adjusting for potential explanatory variables. The large cohort and detailed clinical history allows an evaluation of the impact of TB infection by site of disease. In addition to providing an evidence base on the continued impact of TB coinfection in high resource settings in the ART era, the study provides an assessment of current public health policies with regard to testing, treatment and prevention of HIV and TB infections.

\section{METHODS}

\section{Data sources}

Data from the national HIV cohort were linked to the national enhanced TB surveillance system (ETS) and the death register of the Office for National Statistics. HIV and TB databases are held securely at Public Health England and comply with the data protection legislation. ${ }^{5}{ }^{16}$ Clinic, laboratory and death records within and across years are routinely linked to form a national
HIV cohort. No names are collected on HIV databases at Public Health England. Linking is conducted using a coding system of the surname, gender and date of birth. This cohort includes comprehensive demographic and exposure category information on all adults (aged $\geq 15$ years) diagnosed with HIV infection and prospective clinical information obtained at least annually from all HIV clinics as well as ART usage and all sequential CD4 counts reported directly by laboratories.

TB cases among the HIV cohort were identified using probabilistic record linkage with ETS consisting of demographic and microbiological information and clinical outcomes. Matches were based on the agreement, partial agreement or disagreement between data fields in pairs of records based on initial work by Newcombe ${ }^{17}$ and tailored to the use of infectious disease surveillance data. ${ }^{18}$

\section{Study population and observation time}

We carried out a retrospective cohort study and included all persons aged $\geq 15$ years, diagnosed with HIV infection in England, Wales and Northern Ireland (EWNI) between 2000 and 2008. Patients entered the cohort upon first recorded HIV diagnosis or tests indicating the diagnosis (eg, first CD4 count) and exited at date last seen for HIV care prior 2008 or date of death (if applicable). All remaining observations were censored at the end of 2008. Deaths occurring between 2000 and 2008 were analysed as recorded by 31 December 2010 (box 1).

\section{Data analysis}

After cleaning and deduplication of the merged databases, we described the clinical and demographic characteristics of the HIV cohort with and without TB coinfection. Descriptive analysis included cross-tabulations and calculation of mean values and medians as appropriate. Significance tests were performed with $t$ tests for parametric and Wilcoxon rank-sum tests for nonparametric data. Proportions were compared with $\chi^{2}$ tests.

We analysed survival using a multivariable time-to-event analysis. After checking the validity of the proportional hazards assumption in our data using Schoenfeld's residuals, ${ }^{19}$ we modelled all cause and AIDS-specific time to death with a Cox proportional hazards model. We included variables in a stepwise fashion using Akaike Information Criterion ${ }^{20}$ to decide on the additional explanatory power of each candidate predictor while controlling for model parsimony. For AIDS-specific

\section{Box 1 Definitions}

- TB disease was defined as having evidence of a positive culture of Mycobacterium TB complex or, in the absence of culture confirmation, clinical and/or radiological evidence of TB with report of a full course of anti-TB treatment. Pulmonary and extrapulmonary TB events were both considered. TB events could precede the first HIV diagnosis by 1 year, as late HIV diagnosis is a likely occurrence in this population group. ${ }^{16}$ Earlier TB events were excluded from analysis.

- Late HIV diagnosis was defined as an HIV diagnosis with a CD4 count $<350$ cells $/ \mu \mathrm{L}$ reported within 91 days of diagnosis.

- Simultaneous HIV/TB coinfection was defined as occurrence of these diagnoses within 91 days of each other. ${ }^{16}$ 
survival analysis, non-AIDS deaths were modelled alongside AIDS-related deaths within a 'competing risks' framework.

Variables showing a statistically significant effect and where effect modification was clinically plausible were tested for interactions. We took the magnitude of HRs and the width of their CIs into account to decide whether associations were clinically as well as statistically significant. Data analysis was carried out using STATA V.12 (Stata Corporation, College Station, Texas,
USA) and MS Excel 2010 (Microsoft Corporation, Redmond, Washington, USA) for figures.

\section{RESULTS}

\section{Baseline characteristics}

Table 1 shows the baseline characteristics of the cohort, stratified by TB-HIV coinfection. The cohort consisted of all 44050 persons diagnosed with HIV and seen for care in EWNI

Table 1 Baseline characteristics of a national HIV cohort diagnosed between 2000 and 2008 in England, Wales and Northern Ireland, stratified by TB coinfection

\begin{tabular}{|c|c|c|c|c|c|c|}
\hline & \multicolumn{2}{|c|}{ Not coinfected } & \multicolumn{2}{|c|}{ TB-HIV coinfected } & \multirow{2}{*}{$\begin{array}{l}\text { Total } \\
\text { Number }\end{array}$} & \multirow[b]{2}{*}{ Per cent } \\
\hline & Number & Per cent & Number & Per cent & & \\
\hline Total cases & 40862 & 92.8 & 3188 & 7.2 & 44050 & 100.0 \\
\hline Cohort years & 137826.4 & & 11836.8 & & 149663.2 & \\
\hline \multicolumn{7}{|l|}{ Age and sex } \\
\hline Median age (IQR) at HIV diagnosis & 34.4 & $28.8-41.0$ & 34.9 & 29.9-40.4 & 34.5 & $28.8-41.0$ \\
\hline Male sex & 25217 & 61.7 & 1470 & 46.1 & 26687 & 60.6 \\
\hline \multicolumn{7}{|l|}{ Ethnicity } \\
\hline White & 17976 & 44.0 & 299 & 9.4 & 18275 & 41.5 \\
\hline Black-African & 17230 & 42.2 & 2499 & 78.4 & 19729 & 44.8 \\
\hline Black Caribbean and Black-Other & 2285 & 5.6 & 108 & 3.4 & 2393 & 5.4 \\
\hline South Asian & 472 & 1.2 & 76 & 2.4 & 548 & 1.2 \\
\hline Other Asian/Oriental & 660 & 1.6 & 78 & 2.4 & 738 & 1.7 \\
\hline Other/mixed & 1576 & 3.9 & 87 & 2.7 & 1663 & 3.8 \\
\hline \multicolumn{7}{|l|}{ World region of birth } \\
\hline UK & 11568 & 28.3 & 192 & 6.0 & 11760 & 26.7 \\
\hline Africa & 15670 & 38.3 & 2317 & 72.7 & 17987 & 40.8 \\
\hline Asia & 883 & 2.2 & 135 & 4.2 & 1018 & 2.3 \\
\hline Australasia & 258 & 0.6 & 1 & 0.0 & 259 & 0.6 \\
\hline Europe & 2385 & 5.8 & 75 & 2.4 & 2460 & 5.6 \\
\hline Latin America (incl. Caribbean) & 1428 & 3.5 & 35 & 1.1 & 1463 & 3.3 \\
\hline North America & 278 & 0.7 & 4 & 0.1 & 282 & 0.6 \\
\hline Abroad not specified & 198 & 0.5 & 10 & 0.3 & 208 & 0.5 \\
\hline Not known & 8194 & 20.1 & 419 & 13.1 & 8613 & 19.6 \\
\hline \multicolumn{7}{|l|}{ Probable route of transmission } \\
\hline Sex between men & 15037 & 36.8 & 198 & 6.2 & 15235 & 34.6 \\
\hline Injecting drug use & 676 & 1.7 & 58 & 1.8 & 734 & 1.7 \\
\hline Heterosexual sex & 23667 & 57.9 & 2839 & 89.1 & 26506 & 60.2 \\
\hline Blood/blood products & 124 & 0.3 & 12 & 0.4 & 136 & 0.3 \\
\hline Mother-to-child trans & 20 & 0.0 & 2 & 0.1 & 22 & 0.0 \\
\hline Other/Not known & 1338 & 3.3 & 79 & 2.5 & 1417 & 3.2 \\
\hline \multicolumn{7}{|l|}{ CD4 categories } \\
\hline$\geq 500$ & 10329 & 25.3 & 214 & 6.7 & 10543 & 23.9 \\
\hline $350-499$ & 8191 & 20.0 & 309 & 9.7 & 8500 & 19.3 \\
\hline $200-349$ & 9611 & 23.5 & 603 & 18.9 & 10214 & 23.2 \\
\hline 100-199 & 5462 & 13.4 & 727 & 22.8 & 6189 & 14.0 \\
\hline $50-99$ & 2696 & 6.6 & 488 & 15.3 & 3184 & 7.2 \\
\hline$<50$ & 4573 & 11.2 & 847 & 26.6 & 5420 & 12.3 \\
\hline \multicolumn{7}{|l|}{ Start of ART after HIV diagnosis } \\
\hline ART start $<91$ days & 12415 & 30.4 & 1331 & 41.8 & 13746 & 31.2 \\
\hline ART start $91-365$ days & 6525 & 16.0 & 760 & 23.8 & 7285 & 16.5 \\
\hline ART start $>365$ days & 10561 & 25.8 & 655 & 20.5 & 11216 & 25.5 \\
\hline Never on ART & 10926 & 26.7 & 409 & 12.8 & 11335 & 25.7 \\
\hline ART interruption & 3229 & 10.9 & 259 & 9.4 & 3488 & 10.8 \\
\hline \multicolumn{7}{|l|}{ TB site of disease } \\
\hline Pulmonary TB & $\mathrm{n} / \mathrm{a}$ & $\mathrm{n} / \mathrm{a}$ & 1821 & 57.1 & 1821 & 4.1 \\
\hline ExtrapulmonaryTB & $\mathrm{n} / \mathrm{a}$ & $\mathrm{n} / \mathrm{a}$ & 945 & 29.6 & 945 & 2.1 \\
\hline Miliary TB or TB meningitis & $\mathrm{n} / \mathrm{a}$ & $\mathrm{n} / \mathrm{a}$ & 333 & 10.4 & 333 & 0.8 \\
\hline
\end{tabular}

Numbers and proportions are given, except where denoted.

ART, antiretroviral combination therapy. 


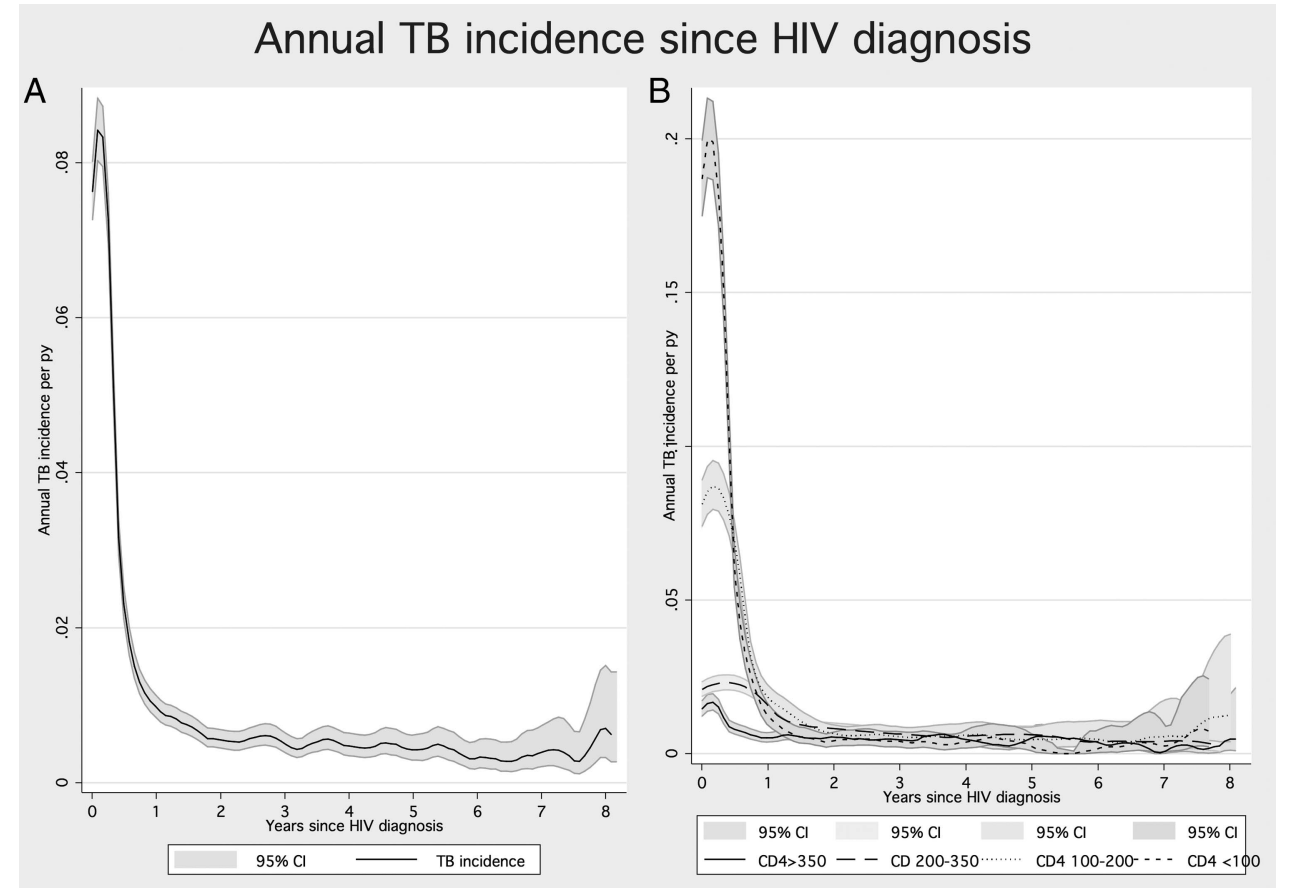

Figure 1 Annual TB incidence density rates among a national HIV cohort $(n=44050)$ diagnosed between 2000 and 2008 in England, Wales and Northern Ireland by time since HIV diagnosis (A) and stratified by CD4 count at HIV diagnosis (B).

between 2000 and 2008 with a total follow-up time of 149663 years and a median follow-up time of 3.1 years. Sixty-one per cent were men and the median age at HIV diagnosis was 34.5 years. The majority of persons were born in SSA $(40.8 \%)$ or the UK (26.7\%), and of Black African (44.8\%) or white ethnicity $(41.5 \%)$. More than half $(56.8 \%)$ were late HIV presenters (table 1).

\section{TB coinfection and incidence density rates}

A total of $3188(7.2 \%)$ persons in the cohort developed TB coinfection during follow-up. Compared with those without $\mathrm{TB}$, the coinfected cohort comprised a higher proportion of women $(p<0.001)$, black Africans born in SSA $(p<0.001)$ and persons reporting heterosexually acquired HIV transmission $(\mathrm{p}<0.001)$. Most patients with TB were diagnosed with HIV late (CD4 count $<350$ cells $/ \mu \mathrm{L} ; 83.6 \%$ ) and consequently ART uptake was high $(87.2 \%)$. The median time between TB and HIV diagnosis was short (35 days, IQR 6-192 days). The most common TB disease was pulmonary TB (PTB, 58.8\%) followed by extra-PTB $(\mathrm{ETB}, 30.5 \%)$ and miliary or central nervous system TB (10.8\%; table 1$)$.

The overall cumulative TB incidence rate of the HIV cohort was 2.13 per 100 person-years (py). The largest TB incidence density rates were observed within 6 months after HIV diagnosis $(9.21$ per 100 py) and dramatically decreased thereafter $(0.72$ and 0.32 per 100 py at 1 and 8 years post HIV diagnosis; figure 1A). Early TB incidence was dramatically affected by CD4 count at diagnosis (figure 1B). The incidence density rate at 6 months in those with a CD4 count $<100$ was 26.6 versus 1.9 per 100 py among those with a CD4 $>350$. TB incidence within 1 year of HIV diagnosis did not show a clear trend during our follow-up time and remained similar (6.92 per 100 py in 2008).

\section{Descriptive analysis of deaths}

A total of $1880(4.3 \%)$ persons died from any cause during follow-up, of whom 898 (47.8\%) were AIDS related. An
AIDS-defining illness prior to or at the time of death was reported for $1162(61.8 \%)$ deaths including 341 persons with TB coinfection (representing 29.3\% of AIDS deaths and 18.1\% of all deaths). Almost two-thirds (64.5\% (220/341)) of deaths among TB coinfected patients occurred within 3 months of simultaneous TB and HIV diagnosis. The median time between HIV diagnosis and death was significantly shorter for coinfection patients compared with those without TB (305 vs 508 days, $\mathrm{p}=0.002)$.

\section{Survival}

Survival was plotted via Kaplan-Meier curves (figure 2A, B), stratified by CD4 categories at HIV diagnosis and TB infection. Figure 2A, B shows that overall and in each CD4 category, the survival probability of TB coinfected patients was lower than in those without TB. Lower survival was particularly marked among patients diagnosed with CD4 count of $<200$ cells $/ \mu \mathrm{L}$. The 1-year probability of survival after HIV diagnosis for TB coinfected patients was $93.2 \%$ (95\% CI 92\% to 94\%) compared with $98 \%$ (95\% CI $97.8 \%$ to $98.1 \%$ ) for those without $(\mathrm{p}<0.001$; table 2). Between 2000 and 2007, 1-year survival improved overall (from 96.5\%; 95\% CI 95.7\% to $97.2 \%$ to 98\%, 95\% CI $97.5 \%$ to $98.3 \%, \mathrm{p}<0.001)$, but not for those with TB coinfection $(92.1 \%, 95 \%$ CI $87.5 \%$ to $95.1 \%$ to $93.2 \%$ $95 \%$ CI $89.4 \%$ to $95.7 \%)$.

In the multivariable Cox proportional hazard model, those with TB coinfection had a 4.8 times higher hazard of death (95\% CI 4.11 to 5.54) compared with those without TB. After stratifying by site of disease, those with miliary TB or TB meningitis had the highest risk (HR 6.96, 95\% CI 5.10 to 9.51), followed by ETB (HR 4.92, 95\% CI 3.92 to 6.17) and PTB (HR $4.32,95 \%$ CI 3.60 to 5.17$)$. Due to low numbers $(n=27)$, it was not possible to include multidrug-resistant tuberculosis (MDR-TB) in the regression model. Other variables significantly associated with worse survival in the multivariable analysis included CD4 <350 at diagnosis, AIDS-defining illnesses other 


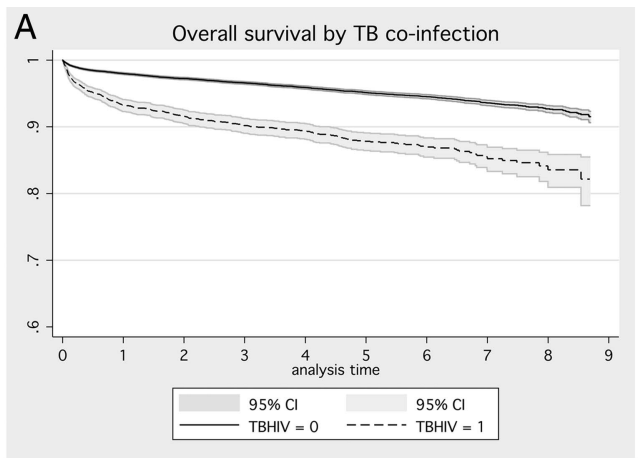

B Survival by CD4 Group
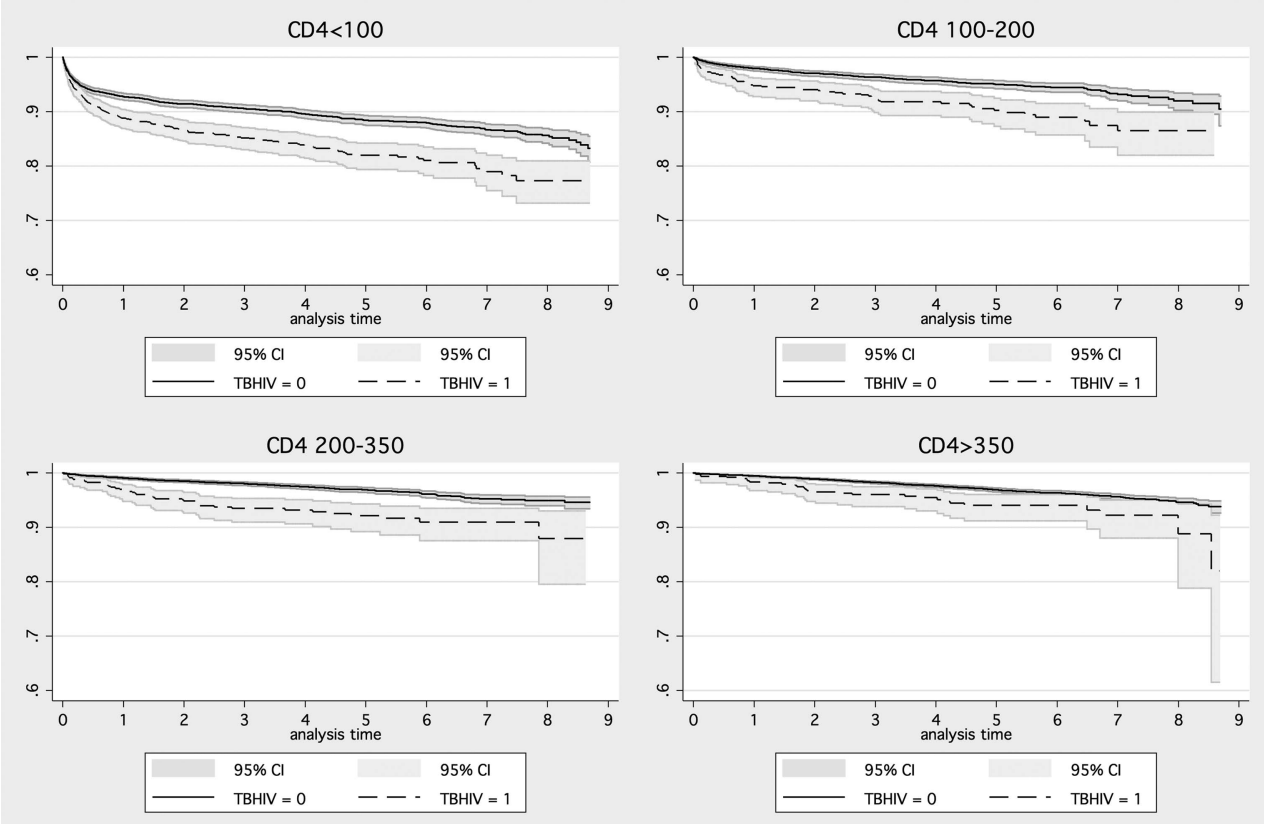

Figure 2 All-cause survival in a national HIV cohort $(n=44050)$ diagnosed between 2000 and 2008 in England, Wales and Northern Ireland stratified by TB-HIV coinfection status (A) and by CD4 count at diagnosis (B).

than TB, never having received ART or late ART start, older age at HIV diagnosis, male sex and injecting drug use or heterosexual sex as probable route of HIV exposure (table 3).

The Cox regression modelling approach was also adopted for AIDS-specific survival and shows very similar results, although with slightly different effect estimates (see online supplementary appendix table). We tested for, but did not find significant evidence of effect modification between exposure variables in both analyses.

\section{DISCUSSION}

We provide national incidence and survival analyses among persons living with HIV and TB coinfection in a high resource country with free and accessible HIV and TB treatment and care. Our findings show that between 2000 and 2008 the incidence of TB among HIV-diagnosed persons remained very high in the first 6 months after HIV diagnoses. After adjusting for a range of factors expected to affect survival, including low CD4 count at diagnosis, the risk of death in TB coinfected patients was almost five times higher than in those without TB coinfection.

The 1-year survival after HIV diagnosis was significantly worse for people with HIV-TB coinfection compared with those without $(93 \%$ vs $98 \%)$. In keeping with improved survival among people diagnosed with HIV in the UK, ${ }^{21}$ we observed an increase in the 1-year survival after HIV diagnosis over the observational period. However, there was no similar trend observed among those coinfected with TB. Overall, nearly onefifth of all deaths in people living with HIV occurred in those with $\mathrm{TB}$, demonstrating the considerable population-level burden imposed by TB.

The magnitude of the impact of TB on survival identified in our cohort was unexpected. A recent meta-analysis of HIV cohort studies primarily observed in SSA found nearly a twofold increase in mortality among TB coinfected persons. However, the small subset of studies conducted in the ART era in high resource settings reported no evidence of increased mortality. ${ }^{10}$ Importantly, most $(80 \%)$ of the $\mathrm{TB}$ coinfected patients in our cohort were born in SSA and were likely to have acquired both infections in their country of origin. The similarities of key clinical features of our TB coinfected cohort with what may be expected in high burden countries-a very low CD4 count at diagnosis, a late or non-start of ART and subsequent ART treatment interruptions ${ }^{7}{ }^{10}$ - may be one explanation for the higher mortality observed in our cohort.

Most deaths in our cohort occurred within the first year (table 2), similar to previous studies. ${ }^{22}$ A large proportion of 
Table 2 Survival probabilities of a national cohort diagnosed between 2000 and 2008 in England, Wales and Northern Ireland by year since HIV diagnosis and TB coinfection

\begin{tabular}{|c|c|c|c|c|}
\hline Cohort time (years) & Number at risk & Deaths & Survival Fn & $95 \% \mathrm{Cl}$ \\
\hline \multicolumn{5}{|c|}{ Patients without TB coinfection } \\
\hline 1 & 31709 & 762 & 0.980 & 0.978 to 0.981 \\
\hline 2 & 25846 & 220 & 0.972 & 0.971 to 0.974 \\
\hline 3 & 20702 & 159 & 0.966 & 0.964 to 0.968 \\
\hline 4 & 15602 & 130 & 0.959 & 0.957 to 0.961 \\
\hline 5 & 11134 & 108 & 0.951 & 0.949 to 0.954 \\
\hline 6 & 7293 & 60 & 0.945 & 0.942 to 0.948 \\
\hline 7 & 4234 & 55 & 0.936 & 0.932 to 0.940 \\
\hline 8 & 1771 & 27 & 0.927 & 0.922 to 0.932 \\
\hline \multicolumn{5}{|l|}{ TB coinfected patients } \\
\hline 1 & 2578 & 205 & 0.932 & 0.923 to 0.941 \\
\hline 2 & 2216 & 43 & 0.916 & 0.905 to 0.925 \\
\hline 3 & 1840 & 31 & 0.902 & 0.890 to 0.912 \\
\hline 4 & 1451 & 15 & 0.894 & 0.881 to 0.905 \\
\hline 5 & 1047 & 22 & 0.878 & 0.864 to 0.891 \\
\hline 6 & 655 & 8 & 0.870 & 0.855 to 0.883 \\
\hline 7 & 360 & 9 & 0.852 & 0.833 to 0.869 \\
\hline 8 & 144 & 4 & 0.836 & 0.809 to 0.859 \\
\hline
\end{tabular}

individuals with low initial CD4 count and/or TB coinfection in the cohort had a late ART initiation. Although delays between HIV diagnosis and ART initiation reduced over the observation period (196-164 days for those with CD4 <350), some delays persisted throughout the entire cohort time and featured as an independent risk factor for poor survival after adjusting for late diagnosis. Historically, delays in ART initiation until 2 months into TB treatment used to be common for fear of toxicity, pill burden and convalescent immunological changes. ${ }^{23}$ The importance of early ART initiation among TB coinfected patients has been demonstrated in the UK ${ }^{15}$ and elsewhere. ${ }^{10}{ }^{24}$ Current guidelines recommend starting ART as soon as practicable in TB coinfected individuals, particularly in those with advanced immunodeficiency. ${ }^{25}$ The observed increased short-term and long-term mortality among patients with late or non-start of ART and low CD4 count in our study supports current recommendations. $^{25}$

The analyses of this paper are based on the very complete national TB surveillance system linked to a large and comprehensive national HIV cohort from the time of diagnosis and up to 9 years of follow-up, with few losses to follow-up. Linking provided the unique opportunity to include TB disease at the time of, and prior to, HIV diagnosis. We observed that the majority of HIV and TB diagnoses were made simultaneously, resulting in a prominent peak in TB incidence within the first few months of HIV diagnosis. Consequently, we show $\mathrm{TB}$ incidence rates among HIV diagnosed to be much higher than observed in clinical HIV cohorts both in the $\mathrm{UK}^{26}$ and in other European cohorts. ${ }^{27}$

In the UK, diagnosed persons with HIV infection who are promptly linked to and retained in care ${ }^{28}$ and those diagnosed at CD4 >350 can expect a near normal life expectancy. ${ }^{11}$ The decreased survival found in our study is largely the result of late HIV diagnosis and delayed start of treatment. This represents considerable missed opportunity for early HIV diagnosis and treatment, particularly among persons from SSA. It highlights the importance of early HIV testing in primary and secondary care settings in high-prevalence areas as recommended by national guidance. ${ }^{25}$
Our study also emphasises the need for TB prevention activities among patients living with diagnosed HIV infection. There is evidence that treatment for latent TB infection (LTBI) in HIV-positive individuals is effective in preventing TB disease. $^{29} 30$ Intensified LTBI screening and treatment among migrants from high TB incidence countries and those with low CD4 count are recommended in the UK. ${ }^{24}{ }^{25}$ Strengthening its implementation may help preventing $\mathrm{TB}$ coinfection in the almost $40 \%$ who did not have a simultaneous diagnosis.

This study has a number of limitations. The cohort comprises persons living with diagnosed HIV, and persons presenting with TB disease not tested for HIV infection will have been missed. Although HIV screening is recommended for all patients diagnosed with TB, implementation of this policy is variable across TB clinics. It is likely that TB patients with undiagnosed HIV would have worse outcomes. Underdiagnosis of HIV infection in TB patients may have therefore lead to an overestimate of observed survival rates among coinfected patients. Results of the multivariate analyses rely on the availability of information collected through routine surveillance; although completion rates are generally high, these may be subject to small misclassification errors. Factors such as other comorbidities are not routinely collected in either surveillance system and are therefore not included in the model. Furthermore, some variables (eg, ART start variable) and late survival estimates could be influenced by a degree of survivor bias, which would underestimate late mortality or TB incidence by excluding early deaths from calculations. Finally, while deaths and death dates are recorded with near-complete accuracy in the UK through linking with the Office of National Statistics, there is a potential for misclassification of the cause of death.

In conclusion, the results of this large national cohort study demonstrate high rates of TB coinfection and subsequent mortality in people living with HIV, even after adjusting for confounders including CD4 count and ART treatment. As the burden of unrecognised HIV and TB infection in the UK remains high, there is a need to improve efforts for early detection and intervention for both HIV and TB. Our findings support recommendations for LTBI screening among HIV infected individuals from TB high incidence areas and 
Table 3 Results of the single and multivariable Cox regression analysis of all-cause mortality in the national HIV cohort $(n=44$ 050) 20002008, England, Wales and Northern Ireland

\begin{tabular}{|c|c|c|c|c|c|c|}
\hline Characteristic & Number & $\begin{array}{l}\text { HR } \\
\text { (unadjusted) }\end{array}$ & $95 \% \mathrm{Cl}$ & $\begin{array}{l}\text { Hazard ratio } \\
\text { (adjusted) }\end{array}$ & $95 \% \mathrm{Cl}$ & $p$ Value \\
\hline \multicolumn{7}{|l|}{ TB-HIV } \\
\hline Yes & 3188 & 2.663 & 2.368 to 2.995 & 4.774 & 4.114 to 5.540 & $<0.001$ \\
\hline No & 40862 & 1.000 & & & & \\
\hline \multicolumn{7}{|l|}{ Site of TB disease } \\
\hline Pulmonary TB & 1821 & 2.440 & 2.091 to 2.847 & 4.316 & 3.604 to 5.169 & $<0.001$ \\
\hline Extrapulmonary TB & 945 & 2.606 & 2.129 to 3.19 & 4.918 & 3.922 to 6.168 & $<0.001$ \\
\hline Miliary TB or TB meningitis & 333 & 4.113 & 3.103 to 5.451 & 6.961 & 5.096 to 9.509 & $<0.001$ \\
\hline No TB & 40862 & 1.000 & & & & \\
\hline \multicolumn{7}{|l|}{ Earliest CD4 } \\
\hline $\mathrm{CD} 4<100$ & 8604 & 4.939 & 4.398 to 5.547 & 3.532 & 2.983 to 4.182 & $<0.001$ \\
\hline CD4 100-199 & 6189 & 2.032 & 1.747 to 2.364 & 2.789 & 2.317 to 3.356 & $<0.001$ \\
\hline CD4 200-349 & 10214 & 1.180 & 1.011 to 1.377 & 1.822 & 1.538 to 2.159 & $<0.001$ \\
\hline CD4 >350 & 19043 & 1.000 & & & & \\
\hline \multicolumn{7}{|l|}{ AIDS (excl. TB) } \\
\hline Yes & 3625 & 8.490 & 7.748 to 9.302 & 7.380 & 6.456 to 8.436 & $<0.001$ \\
\hline No & 40425 & 1.000 & & & & \\
\hline \multicolumn{7}{|l|}{ Age at HIV diagnosis (years) } \\
\hline $15-24$ & 4937 & 0.720 & 0.579 to 0.894 & 0.887 & 0.706 to 1.115 & 0.3 \\
\hline $25-34$ & 18190 & 1.000 & & & & \\
\hline $35-44$ & 14102 & 1.713 & 1.527 to 1.921 & 1.586 & 1.404 to 1.792 & $<0.001$ \\
\hline $45-54$ & 4903 & 2.736 & 2.389 to 3.133 & 2.215 & 1.911 to 2.568 & $<0.001$ \\
\hline$>55$ & 1918 & 5.215 & 4.478 to 6.073 & 3.580 & 3.021 to 4.242 & $<0.001$ \\
\hline \multicolumn{7}{|l|}{ Sex } \\
\hline Female & 17363 & 0.672 & 0.609 to 0.742 & 0.745 & 0.659 to 0.841 & $<0.001$ \\
\hline Male & 26687 & 1.000 & & & & \\
\hline \multicolumn{7}{|l|}{ Start of ART (if $C D 4<350$ ) } \\
\hline Never on ART & 2836 & 5.850 & 5.134 to 6.666 & 5.875 & 4.759 to 7.252 & $<0.001$ \\
\hline ART start $>365$ days & 4712 & 0.532 & 0.442 to 0.639 & 1.328 & 1.133 to 1.558 & $<0.001$ \\
\hline ART start $91-365$ days & 5483 & 1.150 & 1.000 to 1.322 & 1.618 & 1.410 to 1.857 & $<0.001$ \\
\hline ART start $<91$ days & 11693 & 1.000 & & & & \\
\hline \multicolumn{7}{|l|}{ ART interruption (if ever on ART) } \\
\hline No & 28759 & 0.996 & 0.842 to 1.177 & 0.598 & 0.503 to 0.712 & $<0.001$ \\
\hline Yes & 3488 & 1.000 & & & & \\
\hline \multicolumn{7}{|l|}{ Probable route of exposure } \\
\hline Injecting drug use & 734 & 3.794 & 3.034 to 4.744 & 3.701 & 2.907 to 4.713 & $<0.001$ \\
\hline Heterosexual sex & 26506 & 1.160 & 1.048 to 1.285 & 1.212 & 1.052 to 1.396 & 0.008 \\
\hline Blood/blood products recipient & 136 & 1.320 & 0.626 & 2.782 & & \\
\hline Mother-to-child transmission & 22 & 1.673 & 0.235 & 11.898 & & \\
\hline MSM & 15235 & 1.000 & & & & \\
\hline \multicolumn{7}{|l|}{ Region of birth } \\
\hline Western non-UK & 2742 & 0.650 & 0.527 to 0.800 & 0.727 & 0.586 to 0.901 & 0.004 \\
\hline SSA & 17987 & 0.696 & 0.630 to 0.769 & 0.808 & 0.702 to 0.930 & 0.003 \\
\hline Other & 2948 & 0.648 & 0.532 to 0.789 & 0.707 & 0.574 to 0.870 & 0.001 \\
\hline UK & 11760 & 1.000 & & & & \\
\hline \multicolumn{7}{|l|}{ Ethnicity } \\
\hline Black-Caribbean & 1510 & 0.860 & 0.663 & 1.114 & & \\
\hline Black-African & 19729 & 0.828 & 0.751 & 0.913 & & \\
\hline Black-Other/Black-Unspecified & 883 & 0.634 & 0.426 & 0.943 & & \\
\hline Indian/Pakistani/Bangladeshi & 548 & 0.909 & 0.601 & 1.375 & & \\
\hline Other/mixed & 1663 & 0.581 & 0.429 & 0.786 & & \\
\hline Other Asian/Oriental & 738 & 0.722 & 0.481 & 1.083 & & \\
\hline Not known & 704 & 2.984 & 2.318 & 3.840 & & \\
\hline White & 18275 & 1.000 & & & & \\
\hline \multicolumn{7}{|l|}{ MDR-TB } \\
\hline Yes & 27 & 3.330 & 1.470 & 7.544 & & \\
\hline No & 1685 & 1.000 & & & & \\
\hline
\end{tabular}


Table 3 Continued

\begin{tabular}{|c|c|c|c|c|c|c|}
\hline Characteristic & Number & $\begin{array}{l}\text { HR } \\
\text { (unadjusted) }\end{array}$ & $95 \% \mathrm{Cl}$ & $\begin{array}{l}\text { Hazard ratio } \\
\text { (adjusted) }\end{array}$ & $95 \% \mathrm{Cl}$ & p Value \\
\hline \multicolumn{7}{|l|}{ INH-resistant TB } \\
\hline Yes & 128 & 1.599 & 0.992 to 2.577 & & & \\
\hline No & 1757 & 1.000 & & & & \\
\hline \multicolumn{7}{|c|}{ Year of HIV diagnosis } \\
\hline 2000 & 2729 & 1.000 & & & & \\
\hline 2001 & 3673 & 0.872 & 0.718 to 1.058 & & & \\
\hline 2002 & 4432 & 0.971 & 0.803 to 1.174 & & & \\
\hline 2003 & 5341 & 0.839 & 0.690 tot 1.019 & & & \\
\hline 2004 & 5828 & 0.896 & 0.737 to 1.090 & & & \\
\hline 2005 & 5996 & 0.907 & 0.741 to 1.111 & & & \\
\hline 2006 & 5429 & 0.901 & 0.725 to 1.120 & & & \\
\hline
\end{tabular}

increased HIV testing in a wide range of primary and secondary care settings.

\section{Author affiliations}

${ }^{1}$ Respiratory Diseases Department, Centre for Infectious Disease Surveillance and Control, Public Health England, London, UK

${ }^{2}$ Research Department of Infection and Population Health, University College London, London, UK

${ }^{3}$ Division of Medicine, University College London, London, UK

${ }^{4}$ Erasmus MC University Medical Center, Sophia Children's Hospital, Rotterdam, Netherlands

${ }^{5}$ Chelsea \& Westminster Hospitals NHS Foundation Trust, London, UK

Acknowledgements The authors are grateful for the review and constructive suggestions from Dr Andre Charlett, Head of the Statistics Unit in the Centre of Infectious Disease Surveillance and Control, Public Health England, Colindale.

Contributors DZ proposed the study, drafted the research plan, working closely with IA and VD. SC and DZ performed the statistical analysis. DZ drafted the first draft of the manuscript and all authors revised and edited the manuscript. ML and AP provided expert clinical input to the interpretation of the results. VD provided senior supervision. All authors have seen and approved the final version of the manuscript.

Competing interests None declared.

Provenance and peer review Not commissioned; internally peer reviewed.

Transparency declaration We affirm that the manuscript is an honest, accurate and transparent account of the study being reported and no important aspects of the study have been omitted. We confirm that the study was carried out as planned.

\section{REFERENCES}

1 World Health Organisation. Global Tuberculosis Report 2012. 2012. http://apps. who.int/iris/bitstream/10665/75938/1/9789241564502_eng.pdf

2 Joint United Nations Programme on HIVIAIDS (UNAIDS). UNAIDS report on the Global AIDS Epidemic, 2012. 2012. http://www.unaids.org/globalreport/global_ report.htm

3 Public Health England. HIV in the United Kingdom 2013 report. 2013. http://www. hpa.org.uk/Publications/InfectiousDiseases/HIVAndSTIs/1311HIVintheUk2013report/

4 European Centre for Disease Prevention and Control. Tuberculosis surveillance and monitoring in Europe 2014. 2014. http://www.ecdc.europa.eu/en/publications/_ layouts/forms/Publication_DispForm. aspx?List=4f55ad51-4aed-4d32b960-af70113dbb90\&ID $=1050$

5 Public Health England. Tuberculosis in the UK. 2013 report. 2013. http://www.hpa. org.uk/webc/HPAwebFile/HPAweb_C/1317139689583

6 Podlekareva DN, Panteleev AM, Grint D, et al. Short and long term mortality and causes of death in HIV/TB patients in Europe. Eur Respir J 2014;43:166-77.

7 Waitt CJ, Squire SB. A systematic review of risk factors for death in adults during and after tuberculosis treatment. Int I Tuberc Lung Dis 2011;15:871-85.

8 Abdool Karim SS, Naidoo K, Grobler A, et al. Timing of initiation of antiretroviral drugs during tuberculosis therapy. N Engl J Med 2010;362:697-706.

9 Blanc FX, Sok T, Laureillard D, et al. Earlier versus later start of antiretroviral therapy in HIV-infected adults with tuberculosis. N Engl J Med 2011;365:1471-81.
10 Straetemans M, Bierrenbach A, Nagelkerke N, et al. The effect of tuberculosis on mortality in HIV positive people: a meta-analysis. PLOS ONE 2010;5:e15241.

11 May MT, Gompels M, Delpech V, et al. Impact on life expectancy of HIV-1 positive individuals of CD4+ cell count and viral load response to antiretroviral therapy: UK cohort study. AIDS 2014;28:1193-202.

12 Chadborn TR, Delpech VC, Sabin CA, et al. The late diagnosis and consequent short-term mortality of HIV-infected heterosexuals (England and Wales, 20002004). AIDS 2006;20:2371-9.

13 Ahmed AB, Abubakar I, Delpech $V$, et al. The growing impact of HIV infection on the epidemiology of tuberculosis in England and Wales: 1999-2003. Thorax 2007;62:672-6.

14 Dheda K, Lampe FC, Johnson MA, et al. Outcome of HIV-associated tuberculosis in the era of highly active antiretroviral therapy. J Infect Dis 2004;190:1670-6.

15 Dean GL, Edwards SG, Ives NJ, et al. Treatment of tuberculosis in HIV-infected persons in the era of highly active antiretroviral therapy. AIDS 2002;16:75-83.

16 Rice B, Elford J, Yin Z, et al. Decreasing incidence of tuberculosis among heterosexuals living with diagnosed HIV in England and Wales. AIDS 2013;27:1151-7.

17 Newcombe HB. Handbook of record linkage. Oxford University Press, 1988.

18 Potz N, Powell D. Manual for the probabilistic linkage of infection and death records. Health Protection Agency, 2007.

19 Schoenfeld D. Partial residuals for the proportional hazards regression model. Biometrika 1982;69:239.

20 Akaike H. A new look at the statistical model identification. In: Parzen E, Tanabe K, Kitagawa G, eds. Selected papers of hirotugu akaike. New York: Springer, 1998. 215-22.

21 Simmons RD, Ciancio $B C$, Kall MM, et al. Ten-year mortality trends among persons diagnosed with HIV infection in England and Wales in the era of antiretroviral therapy: AIDS remains a silent killer. HIV Med 2013;14:596-604.

22 Taarnhøj G, Engsig F, Ravn P, et al. Incidence, risk factors and mortality of tuberculosis in Danish HIV patients 1995-2007. BMC Pulm Med 2011:11:1471-2466:26.

23 Michailidis C, Pozniak AL, Mandalia S, et al. Clinical characteristics of IRIS syndrome in patients with HIV and tuberculosis. Antivir Ther (Lond) 2005;10:417-22.

24 Harries AD, Lawn SD, Getahun H, et al. HIV and tuberculosis-science and implementation to turn the tide and reduce deaths. J Int AIDS Soc 2012;15.

25 Pozniak AL, Coyne KM, Miller RF, et al. British HIV Association guidelines for the treatment of TB/HIV coinfection 2011. http://www.bhiva.org/documents/Guidelines/ TB/hiv_954_online_final.pdf

26 Grant AD, Bansi L, Ainsworth J, et al. Tuberculosis among people with HIV infection in the United Kingdom: opportunities for prevention? AIDS 2009:23:2507-15.

27 Karo B, Haas W, Kollan C, et al. Tuberculosis among people living with HIVIAIDS in the German ClinSurv HIV Cohort: long-term incidence and risk factors. BMC Infect Dis 2014;14:148.

28 Delpech V, Brown AE, Croxford S, et al. Quality of HIV care in the United Kingdom: key indicators for the first 12 months from HIV diagnosis. HIV Med 2013;14(Suppl 3):19-24.

29 Wilkinson D. Drugs for preventing tuberculosis in HIV infected persons. Cochrane Database Syst Rev 2000;(4):CD000171 .http://ovidsp.ovid.com/ovidweb.cgi?T=JS\&CSC= $Y \& N E W S=N \& P A G E=f u l l t e x t \& D=e m e d 5 \& A N=11034676$ (accessed 8 Jun 2012).

30 Woldehanna S, Volmink J. Treatment of latent tuberculosis infection in HIV infected persons. Cochrane Database Syst Rev 2004;(1):CD000171 .http://ovidsp.ovid.com/ ovidweb.cgi? T=JS\&CSC $=$ Y\&NEWS=N\&PAGE=fulltext\&D=emed6\&AN=14973947 (accessed 8 Jun 2012). 